\title{
Uso de inoculante $A$ zospirillum brasilense na produção de mudas de Tento Carolina
}

\author{
Use of inoculant Azospirillum brasilense in the production of seedllings of Tento Carolina \\ Uso del inoculante Azospirillum brasilense en la producción de plántulas de Tento Carolina
}

Recebido: 23/12/2020 | Revisado: 25/12/2020 | Aceito: 28/12/2020 | Publicado: 02/01/2021

Luciana Santos Almeida

ORCID: https://orcid.org/0000-0001-9981-8512

Universidade do Estado de Mato Grosso, Brasil

E-mail: lucianadealmeida.agro@gmail.com

Severino de Paiva Sobrinho

ORCID: https://orcid.org/0000-0002-7989-8145

Universidade do Estado de Mato Grosso, Brasil

E-mail: paivasevero@unemat.br

Petterson Baptista da Luz

ORCID: https://orcid.org/0000-0003-4067-0087

Universidade do Estado de Mato Grosso, Brasil

E-mail: paivasevero@unemat.br

Daniela Soares Alves Caldeira

ORCID: https://orcid.org/0000-0002-4345-3718

Universidade do Estado de Mato Grosso, Brasil

E-mail: danielacaldeira@unemat.br

Altacis Junior de Oliveira

ORCID: https://orcid.org/0000-0002-6787-7160 Universidade do Estado de Mato Grosso, Brasil

E-mail: juniormarques11@gmail.com

Taniele Carvalho de Oliveira

ORCID: https://orcid.org/0000-0002-6900-6449 Universidade do Estado de Mato Grosso, Brasil E-mail: tani.ele@hotmail.com

Marcella Karoline Cardoso Vilarinho

ORCID: https://orcid.org/0000-0003-1410-142X Universidade do Estado de Mato Grosso, Brasil E-mail: marcella.vilarinho@unemat.br

Carlos Luiz Vieira

ORCID: https://orcid.org/0000-0003-4457-3743 Universidade do Estado de Mato Grosso, Brasil

E-mail: carlos.luiz_12@hotmail.com.br

Alex Sandro Poquiviqui da Silva

ORCID: https://orcid.org/0000-0002-4468-9829 Universidade do Estado de Mato Grosso, Brasil

E-mail: alexpockevicke403@gmail.com

Gabriel Vinicius Batista da Silva

ORCID: https://orcid.org/0000-0003-1183-5866 Universidade do Estado de Mato Grosso, Brasil

E-mail: gabriel.vinicius.sil@unemat.br

\begin{abstract}
Resumo
As Bactérias diazotróficas Azospirillum brasilense são benéficas para as plantas devido à capacidade de quebrar a molécula de N2, facilitando sua assimilação pelas plantas, além disso, é considerada promotora de crescimento vegetativo, pois, induzem na produção e liberação de fitormônios como auxinas, giberelinas e citocininas, responsáveis pelo crescimento vegetativo e expansão do sistema radicular. Devido à espécie de Tento Carolina ser bastante utilizada em arborização urbana e em áreas de reflorestamento, objetivou-se neste trabalho avaliar o efeito da inoculação de Azospirillum brasilense, em diferentes doses, no desenvolvimento de mudas de Tento Carolina (Adenanthera pavonina L.). A pesquisa foi composta por um ensaio com delineamento experimental inteiramente casualizado com seis tratamentos, quatro repetições e quatro plantas por parcela. As doses utilizadas foram: T1: $0 \mathrm{ml}$ (testemunha); T2: 0,3 ml; T3: 0,6 ml; T4: 0,9 ml; T5: $1,2 \mathrm{ml}$ e T6: $1,5 \mathrm{ml}$ ) para 30 gramas de sementes. O experimento foi conduzido em casa de vegetação, no município de Cáceres, MT. As avaliações morfológicas das plantas foram realizadas 120 dias após a semeadura. Os dados foram submetidos ao programa computacional R, aplicando-se o teste $\mathrm{F}$ para diagnóstico de efeito significativo, e as médias comparadas pelo teste Tukey a 5\% de probabilidade. Os resultados obtidos apontam que houve diferença significativa entre os tratamentos com utilização de Azospirillum brasilense, e somente para as variáveis de número de folhas e relação altura da parte aérea/diâmetro
\end{abstract}


do coleto seu uso foi indiferente. Nenhum tratamento com inoculante apresentou resultado superior ao tratamento denominado testemunha.

Palavras-chave: Adenanthera pavonina L.; Bactérias diazotróficas; Fixação biológica.

\begin{abstract}
The diazotrophic bacteria Azospirillum brazilense are beneficial for the plants due to the ability to break the molecule of N2, facilitating its assimilation by the plants, moreover, it is considered a promoter of vegetative growth, because they induce in the production and release of phytohormones such as auxins, gibberellins and cytokines, responsible for vegetative growth and expansion of the root system. Due to the species of Tento Carolina being widely used in urban arborization and in reforestation areas, the objective of this work was to evaluate the effect of the inoculation of Azospirillum brasilense, in different doses, in the development of seedlings of Tento Carolina (Adenanthera pavonina L.). The research was composed by an experimental design entirely randomized with six treatments, four repetitions and four plants per plot. The doses used were: T1: $0 \mathrm{ml}$ (witness); T2: $0.3 \mathrm{ml}$; T3: $0.6 \mathrm{ml}$; T4: $0.9 \mathrm{ml}$; T5: $1.2 \mathrm{ml}$ and T6: $1.5 \mathrm{ml}$ ) for 30 grams of seeds. The experiment was conducted in a green house in the municipality of Cáceres, MT. Morphological evaluations of the plants were performed 120 days after sowing. The data were submitted to computer program $\mathrm{R}$, applying the $\mathrm{F}$ test for diagnosis of significant effect, and the means compared by the Tukey test at $5 \%$ probability. The results obtained indicate that there was a significant difference between the treatments using Azospirillum brasilense, and only for the variables of number of leaves and relation height of the aerial part/diameter of the collection its use was indifferent. No treatment with inoculant presented superior result to the treatment called witness.
\end{abstract}

Keywords: Adenanthera pavonina L.; Diazotrophic bacteria; Biological fixation.

\title{
Resumen
}

La bacteria diazotrófica Azospirillum brasilense es beneficiosa para las plantas debido a la capacidad de romper la molécula de N2, facilitando su asimilación por las plantas, además, se considera un promotor del crecimiento vegetativo, porque induce en la producción y liberación de fitohormonas como auxinas, giberelinas y citoquinas, responsables del crecimiento vegetativo y la expansión del sistema radicular. Debido a que la especie de Tento Carolina se utiliza ampliamente en la arborización urbana y en las zonas de reforestación, el objetivo de este estudio fue evaluar el efecto de la inoculación de Azospirillum brasilense, en diferentes dosis, en el desarrollo de las plántulas de Tento Carolina (Adenanthera pavonina L.). La investigación se compuso de un diseño experimental totalmente aleatorio con seis tratamientos, cuatro repeticiones y cuatro plantas por parcela. Las dosis utilizadas fueron: T1: $0 \mathrm{ml}$ (testigo); T2: 0,3 ml; T3: 0,6 ml; T4: 0,9 ml; T5: 1,2 ml y T6: 1,5 ml) para 30 gramos de semillas. El experimento se llevó a cabo en un invernadero en el municipio de Cáceres, MT. Las evaluaciones morfológicas de las plantas se realizaron 120 días después de la siembra. Los datos fueron sometidos al programa informático R, aplicando la prueba $\mathrm{F}$ para el diagnóstico de efecto significativo, y las medias comparadas por la prueba de Tukey con un 5\% de probabilidad. Los resultados obtenidos indican que hubo diferencias significativas entre los tratamientos que utilizaron Azospirillum brasilense, y sólo para las variables de número de hojas y relación de altura de la parte aérea / diámetro de la colección su uso fue indiferente. Ningún tratamiento con inoculante presentó resultados superiores al tratamiento llamado testigo.

Palabras clave: Adenanthera pavonina L.; Bacterias diazotróficas; Fijación biológica.

\section{Introdução}

A espécie Adenanthera pavonina L., popularmente conhecida como Tento Carolina, Olho-de-dragão ou Falso-PauBrasil, é uma planta originária da Ásia, do tipo leguminosa arbórea, e pertencente à família Fabaceae. No Brasil, seu cultivo acontece há anos, pois, é bastante utilizada no paisagismo e arborização urbana, e devido a sua adaptabilidade a espécie foi amplamente distribuída em quase todo território brasileiro (Gonçalves, 2018; Gugé et al., 2019). De modo geral, a árvore possui bastante aproveitamento, suas folhas e cascas possuem princípios ativos que são utilizados em produtos fitoterapêuticos; as sementes apesar de conter substâncias medicinais são bastante requeridas nas produções artesanais.

No entanto, seu uso é especialmente voltado para a exploração da madeira, pois, a resistência e a rusticidez garantem produtos de ótima qualidade (Oliveira et al., 2012; Gonçalves, 2018). Além disso, grande parte das espécies da família Fabaceae, são recomendadas para o reflorestamento, por possuírem um rápido desenvolvimento vegetativo e formação de copas, gerando sombreamento e auxiliando no crescimento de outras espécies que são sensíveis a alta luminosidade (Soares, 2007). 
A espécie de Tento Carolina, é requerida em áreas degradadas que estão em processo de recuperação, pois, mesmo que de forma pequena, possuem a capacidade de fixar biologicamente o nitrogênio do ar, através da associação de suas raízes com bactérias diazotróficas presentes no solo, fornecendo de forma gradativa a recolonização vegetal, maiores teores de matéria orgânica para o solo, ciclagem de nutrientes etc., (Hungria, 2011; Alves et al., 2015).

Entretanto, nem sempre a população nativa de bactérias diazotróficas do solo são capazes de estabelecer uma associação eficiente com a planta, por isso, novas práticas são elaboradas e adotadas pelos silvicultores. Um exemplo disso é a aplicação, via solo ou sementes, de inoculantes compostos por microrganismos benéficos, e apesar dos estudos com inoculação de espécies florestais serem escassos, é interessante ressaltar que o uso dessa tecnologia apresenta grande potencial para a melhoria na produção de mudas e crescimento vegetativo das plantas (Soares, 2007; Monteiro et al., 2014).

Dentre os grupos de microrganismos benéficos para as plantas, às bactérias do gênero Azospirillum brasilense são utilizadas no processo de inoculação devido à capacidade de quebrar a molécula de $\mathrm{N}_{2}$ facilitando a assimilação do mesmo pelas plantas; e também por induzir a produção e liberação de hormônios vegetais como auxinas, giberelinas e citocininas, que são responsáveis pelo crescimento vegetativo e expansão do sistema radicular (Repke et al., 2013).

Para canafístula, a microbiolização com a estirpe de A. brasilense ou B. elkanii isoladas ou em associação elevou a massa seca de parte aérea, o comprimento de parte aérea e o comprimento do sistema radicular, e reduziram o diâmetro de coleto (Rampim et al., 2014). Em estudo recente com plantas de milho, Veronezi et al. (2018) verificaram que a associação de nitrogênio mais Azospirillum brasilense na semeadura, proporcionou melhoria no desenvolvimento vegetativo da planta, demonstrando que pelo menos em milho a inoculação de sementes tem apresentado resultados promissores.

Diante de alguns resultados em outras espécies e a escassez de informações sobre inoculação de bactérias em sementes de espécies florestais, objetivou-se neste trabalho avaliar o efeito da inoculação de Azospirillum brasilense, em diferentes doses, no desenvolvimento de mudas de Tento Carolina (Adenanthera pavonina L.).

\section{Metodologia}

As sementes de Tento Carolina (Adenanthera pavonina L.) foram coletadas em matrizes localizadas no município de Cáceres-MT, em dezembro de 2019. Realizou-se quebra de dormência das sementes através de escarificação mecânica com lixa preta $\mathrm{N}^{\circ} 36$, já que as mesmas apresentam tegumento do tipo impermeável à água.

Em seguida, foram separados seis lotes de $30 \mathrm{~g}$ de sementes (cerca de 150 a 155 sementes) para receber a aplicação do inoculante. O produto biológico foi doado por uma empresa do ramo agrícola, o mesmo possuía forma líquida composta por Bactérias Azospirilum brasilense nas estirpes ABV5 e ABV6, na concentração de 2x108 bactérias $\mathrm{ml}^{-1}$. As doses de aplicação para os tratamentos tiveram como base a recomendação do produto para a cultura do trigo e milho (100 ml do produto para 60.000 sementes), sendo que para as sementes da espécie em estudo ainda não existem recomendações.

$\mathrm{O}$ delineamento experimental adotado foi o inteiramente casualizado com seis tratamentos, quatro repetições e quatro plantas em cada parcela. As doses utilizadas foram as seguintes: T1: 0,0 mL (testemunha); T2: 0,3 mL; T3: 0,6 mL; T4: 0,9 mL; T5: 1,2 mL e T6: 1,5 mL para 30 gramas de sementes.

A inoculação foi realizada no dia 03 de janeiro de 2020, as sementes foram colocadas em sacos de plástico para facilitar a agitação do produto e com auxílio de uma seringa foi adicionado a dose necessária de cada tratamento. A semeadura foi realizada logo após o processo de inoculação, semeando duas sementes em cada saco de substrato. O experimento foi instalado na casa de vegetação da área experimental do Curso de Agronomia do Campus de Cáceres UNEMAT. O substrato utilizado para a produção das mudas foi coletado na área experimental, sendo as características físico-químicas apresentadas na Tabela 1. 
Tabela 1. Valores das características físico-químicas do solo utilizado como substrato para a produção de mudas de Adenanthera pavonina.

\begin{tabular}{|c|c|c|c|c|c|c|c|c|c|c|}
\hline pH & $\mathbf{P}$ & M.O & $\mathbf{K}$ & $\mathbf{C a}$ & Mg & Al & $\mathbf{H}$ & Areia & Silte & Argila \\
\hline & \multicolumn{2}{|c|}{-----mg dm${ }^{-3}$} & \multicolumn{5}{|c|}{------------------cmol $\mathrm{dm}^{-3}$----------------- } & \multicolumn{3}{|c|}{-------------g kg1'------------- } \\
\hline 5,8 & 5,59 & 47,32 & 0,23 & 4,88 & 1,59 & 0,0 & 2,00 & 692 & 96,60 & 211,40 \\
\hline
\end{tabular}

Fonte: Autores.

Não houve nenhuma aplicação de fertilizantes no solo. O mesmo foi peneirado e distribuído em 96 sacos de polietileno preto, próprio para o plantio de mudas, com capacidade para $600 \mathrm{~cm}^{3}$ de substrato com as dimensões de $8 \mathrm{~cm}$ de largura e $15 \mathrm{~cm}$ de altura. Na casa de vegetação as irrigações eram realizadas através de micro aspersores programados para aplicarem água três vezes ao dia $(06 \mathrm{~h} 00 ; 13 \mathrm{~h} 00$ e 17h30min) com duração de 3,5 minutos por período.

Aos 30 dias, após a semeadura, foi retirado o excesso de plantas dos recipientes, deixando apenas a planta mais vigorosa em cada um deles. Semanalmente era realizada a remoção das plantas daninhas a fim de evitar a competição por espaço, água, luz e nutrientes com as mudas em crescimento. Aos 120 dias, após a semeadura (maio de 2020), procedeu-se a retirada das mudas do substrato para avaliação do crescimento das mesmas.

Para verificar o efeito dos tratamentos foram feitas as seguintes avaliações: altura da parte aérea (H): sendo considerada a distância entre o colo da planta e a gema apical; comprimento da raiz (CR): considerou-se a distância entre o colo da planta e o comprimento da maior raiz, ambos foram medidos com auxílio de régua milimetrada com valores expressos em centímetro; diâmetro do coleto (DC): medido no colo da planta, com auxílio de paquímetro digital e os valores expressos em milímetro; razão entre altura da parte aérea e diâmetro do coleto (H/DC): foi determinado dividindo a altura da parte aérea pelo diâmetro do coleto; Número de folhas por planta (NF): através da contagem do número de folhas presentes em cada planta; massa fresca da parte área (MFPA), massa fresca da raiz (MFR) e massa fresca total (MFT): as plantas foram retiradas dos substratos, seccionadas na região do colo e a parte aérea foi colocada em saco de plástico; a raiz foi lavada para retirada do excesso de solo e também colocada em saco de plástico, em seguida foram levadas para a pesagem em balança de precisão, com valores expressos em gramas.

Em seguida, as partes aéreas e raízes foram colocadas em sacos de papel kraft e levadas à estufa à $65^{\circ} \mathrm{C}$ por 72 horas para obter os dados das seguintes variáveis: massa seca da parte aérea (MSPA), massa seca da raiz (MSR) e massa da seca total (MST), sendo pesadas em balança de precisão, com valores expressos em gramas. Também foi determinado o índice de qualidade de Dickson (IQD), que foi calculado conforme equação proposta por Dickson et al. (1960).

$$
I Q D=\frac{M S T(g)}{\frac{H(c m)}{D C(c m)}+\frac{M S P A(g)}{M S R(g)}}
$$

Onde:

H: altura da parte aérea (cm); DC: diâmetro do coleto (mm); MST: massa seca total (g); MSPA: massa seca da parte aérea (g) e MSR: massa seca da raiz (g).

Os dados das variáveis foram submetidos ao programa computacional R versão 3.6.3, aplicando-se o teste $\mathrm{F}$ para diagnóstico de efeito significativo, com as médias comparadas pelo teste Tukey a 5\% de probabilidade. 


\section{Resultados e Discussão}

De acordo com a Tabela 2, as médias do número de folhas não diferiram entre si, variando de 12,6 a 13,2 com média de 12,95 folhas por planta, apontando que a aplicação da bactéria não causou efeito para esta variável.

Tabela 2. Médias do número de folhas por planta (NF), altura da parte aérea (H), diâmetro do coleto (DC) e comprimento da raiz (CR) de plantas de Adenanthera pavonina em função da aplicação de diferentes doses de Azospoirillum brasilense em sementes.

\begin{tabular}{ccccc}
\hline Doses de inoculante & NF & H $(\mathrm{cm})$ & DC $(\mathrm{mm})$ & CR $(\mathrm{cm})$ \\
\hline T1 $(0,0 \mathrm{~mL}) / 30 \mathrm{~g}$ de sementes & 13,0 & $12,94 \mathrm{ab}$ & $3,24 \mathrm{a}$ & $26,00 \mathrm{ab}$ \\
$\mathrm{T} 2(0,3 \mathrm{~mL}) / 30 \mathrm{~g}$ de sementes & 13,0 & $11,52 \mathrm{bc}$ & $2,81 \mathrm{bcd}$ & $25,44 \mathrm{ab}$ \\
$\mathrm{T} 3(0,6 \mathrm{~mL}) / 30 \mathrm{~g}$ de sementes & 12.8 & $14,34 \mathrm{a}$ & $3,20 \mathrm{ab}$ & $27,33 \mathrm{ab}$ \\
$\mathrm{T} 4(0,9 \mathrm{~mL}) / 30 \mathrm{~g}$ de sementes & 13,2 & $10,65 \mathrm{bc}$ & $2,55 \mathrm{~d}$ & $23,91 \mathrm{~b}$ \\
$\mathrm{~T} 5(1,2 \mathrm{~mL}) / 30 \mathrm{~g}$ de sementes & 12,6 & $10,13 \mathrm{c}$ & $2,61 \mathrm{~cd}$ & $27,74 \mathrm{a}$ \\
$\mathrm{T} 6(1,5 \mathrm{~mL}) / 30 \mathrm{~g}$ de sementes & 13,1 & $11,89 \mathrm{abc}$ & $2,98 \mathrm{abc}$ & $25,67 \mathrm{ab}$ \\
\hline $\mathrm{CV}(\%)$ & 5,35 & 9,54 & 6,11 & 6,37 \\
\hline
\end{tabular}

Médias seguidas da mesma letra na coluna não diferem entre si pelo Tukey a 5\% de probabilidade. Fonte: Autores.

Domingues Neto et al. (2013) ao trabalharem com a aplicação foliar de A. brasilense em milho verde safrinha também constataram que o número médio de folhas não foi incrementado com o uso da bactéria, os mesmos relatam que o benefício do uso de A. brasilense está relacionado com a dose, a época de aplicação e a escolha das estirpes, que variam de acordo com a região e cultura utilizada. Outro estudo recente realizado por Maziero et al. (2019), trabalhando com a aplicação A. brasilense em Angico Vermelho (Anadenanthera macrocarpa) constataram que o número de folhas também não foi influenciado pelas diferentes concentrações testadas naquele estudo.

As mudas de Tento Carolina apresentaram crescimento médio em altura entre 10,13 e 14,34 cm por planta. A maior média ocorreu no tratamento $\mathrm{T}_{3}$ com dose de $0,6 \mathrm{ml}$ para $30 \mathrm{~g}$ de sementes, porém, o mesmo não se diferiu dos tratamentos $\mathrm{T}_{1}$ e $\mathrm{T}_{6}$ (Tabela 02). Entretanto, o comportamento da variável altura de planta apresentou que a aplicação de A. brasilense pode até trazer benefícios para essa característica, mas o resultado não aponta diferença significativa com o tratamento que não houve aplicação da bactéria.

No entanto, Domingues Neto et al. (2014) ao testarem A. brasilense no desenvolvimento vegetativo de aveia preta (Avena strigosa) constataram que o tratamento de sementes, por meio da inoculação, trouxe incrementos na altura de plantas de aveia em relação ao tratamento testemunha. O uso da altura de planta tem sido um dos parâmetros mais utilizados para avaliar a eficiência padrão de qualidade de mudas nos viveiros e para estimar o crescimento delas no campo (Gomes et al., 2002).

Neste trabalho, o diâmetro das mudas de Tento Carolina variou de 2,55 mm a 3,24 mm por planta. A maior média foi obtida para o tratamento $\mathrm{T}_{1}$, sem nenhuma dose de inoculante aplicado, com 3,24 mm, mas não diferiu dos resultados obtidos nos tratamentos $\mathrm{T}_{3}$ e $\mathrm{T}_{6}$ (Tabela 02), sendo esse resultado semelhante ao obtido para altura de planta, tendo como diferença que na variável anterior o maior valor tinha sido no tratamento $\mathrm{T}_{3}$.

De acordo com Delarmelina et al. (2014), a avaliação do diâmetro do coleto é de suma importância, pois, indica se a planta terá maior ou menor capacidade de sobreviver no campo após o transplantio definitivo. Baseando-se nisso, as plantas 
dos tratamentos $\mathrm{T}_{1}$ e $\mathrm{T}_{3}$ teriam maior probabilidade de estabelecimento em campo, devido aos valores mais altos. Estudo realizado com milho verde safrinha por Domingues Neto et al. (2013) também verificaram que a inoculação das sementes com a bactéria não obteve respostas significativas entre os tratamentos para o diâmetro do colmo.

Já nos estudos realizado por Maziero et al. (2019) observaram aumento do diâmetro do coleto de Angico Vermelho (Anadenanthera macrocarpa), confirmando que, os resultados positivos dependem da espécie, doses, tipos de estirpes, regiões e por isso as respostas são controversas de estudo para estudo.

O maior valor de tamanho do sistema radicular ocorreu para o tratamento $\mathrm{T}_{5}$, porém esse diferiu apenas para as os valores obtidos no tratamento $\mathrm{T}_{4}$ (Tabela 02). Segundo Gomes et al. (2003) avaliando o crescimento das mudas de Eucalipto (Eucalyptus grandis) em diferentes recipientes averiguou que o tamanho da embalagem afeta o desenvolvimento radicular de mudas, por isso, o tipo de embalagem utilizado para este experimento pode ter afetado a expansão das raízes, mantendo um tamanho padrão do sistema radicular das mudas de Tento Carolina.

Além disso, pesquisas com o uso de bactérias A. brasilense em importantes culturas como milho, por exemplo, demonstraram que a inoculação modifica a morfologia das raízes, aumentando o número de raízes laterais, favorecendo a absorção dos nutrientes (Cavallet et al., 2000). Conforme relatado em diversos estudos, a inoculação com bactérias promotoras de crescimento de plantas estimula a produção de hormônios que favorece o desenvolvimento das raízes secundárias, além de promover maior número de pelos radiculares.

De acordo com Dartora et al. (2013) relatam em seus estudos que o incremento do sistema radicular, observado em pesquisas com plântulas de trigo, está ligado com a produção do hormônio AIA que é responsável pelo crescimento e expansão das raízes secundárias.

Para a variável de razão de altura de parte aérea e diâmetro de coleto as médias variaram entre 3,69 e 4,19, demonstrando que não houve diferença significativa entre as médias (Tabela 3). Segundo Carneiro (1995) citado por Gomes et al. (2002) a junção das características de altura de parte aérea e diâmetro do coleto é considerado um dos parâmetros morfológicos mais importantes, quando a questão é averiguar a qualidade de mudas após a implantação no campo, o mesmo aponta que essa característica estima o equilíbrio de crescimento das plantas.

Tabela 3. Médias da relação altura da parte aérea e diâmetro do coleto (H/DC), da massa fresca da parte aérea (MFPA), massa fresca da raiz (MFR) e da massa fresca total (MFT) de plantas de Adenanthera pavonina em função da aplicação de diferentes doses de Azospoirillum brasilense em sementes.

\begin{tabular}{|c|c|c|c|c|}
\hline Doses de inoculante & $\mathrm{H} / \mathrm{DC}\left(\mathrm{cm} \cdot \mathrm{mm}^{1}\right)$ & MFPA $(g)$ & $\operatorname{MFR}(g)$ & $\operatorname{MFT}(g)$ \\
\hline $\mathrm{T}_{1}(0,0 \mathrm{~mL}) / 30 \mathrm{~g}$ de sementes & 3,69 & $3,43 \mathrm{ab}$ & $5,41 \mathrm{ab}$ & $8,84 \mathrm{ab}$ \\
\hline $\mathrm{T}_{2}(0,3 \mathrm{~mL}) / 30 \mathrm{~g}$ de sementes & 4,10 & $4,08 \mathrm{a}$ & $3,99 \mathrm{bc}$ & $8,07 \mathrm{~b}$ \\
\hline $\mathrm{T}_{3}(0,6 \mathrm{~mL}) / 30 \mathrm{~g}$ de sementes & 4,47 & $3,71 \mathrm{ab}$ & $6,58 \mathrm{a}$ & $10,29 \mathrm{a}$ \\
\hline $\mathrm{T}_{4}(0,9 \mathrm{~mL}) / 30 \mathrm{~g}$ de sementes & 4,19 & $3,32 \mathrm{ab}$ & $3,45 \mathrm{c}$ & $6,77 \mathrm{~b}$ \\
\hline $\mathrm{T}_{5}(1,2 \mathrm{~mL}) / 30 \mathrm{~g}$ de sementes & 3,89 & $2,93 \mathrm{~b}$ & $5,14 \mathrm{abc}$ & $8,07 \mathrm{~b}$ \\
\hline $\mathrm{T}_{6}(1,5 \mathrm{~mL}) / 30 \mathrm{~g}$ de sementes & 3,98 & $3,70 \mathrm{ab}$ & $4,17 \mathrm{bc}$ & $7,86 b$ \\
\hline $\mathrm{CV}(\%)$ & 7,22 & 11,51 & 16,44 & 11,49 \\
\hline
\end{tabular}


A variável de massa fresca da parte aérea obteve maior média no tratamento T2 com 4,08 gramas por planta, no entanto, não se diferenciou dos tratamentos T1, T3, T4, e T6 e o menor resultado foi obtido no tratamento T5 com 2,93 gramas por planta, que se diferenciou apenas do T2 (Tabela 03). Para a variável massa fresca da raiz e massa fresca total, os melhores resultados foram obtidos no tratamento T3, com 6,58 gramas e 10,29 gramas, porém, para a massa fresca da raiz o tratamento T3 foi superior aos tratamentos T2, T4 e T6 e para a massa fresca total o tratamento T3 foi superior aos tratamentos T2, T4, T5 e T6 (Tabela 03). Estudo realizado por Rampim et al. (2014) demostraram que a estirpe de A. brasilense proporcionou valores superiores aos da testemunha, para MSR e para MSPA para plântulas de leucena e canafístula, respectivamente.

Analisando as médias da variável massa seca de parte aérea na Tabela 4, observou-se que o tratamento T5 apresentou o menor valor e não diferiu da média do tratamento T4 e os tratamentos T1, T2, T3 e T6 apresentaram valores superiores em relação ao tratamento T5, mas não diferiram entre si. Para massa seca da raiz e massa seca total as melhores respostas ocorreram ambas no tratamento $\mathrm{T} 3$, com 1,43 e 2,86 gramas, respectivamente.

Tabela 4. Médias da massa seca da parte aérea (MSPA), da massa seca da raiz (MSR), massa seca total (MST) e do índice de qualidade de Dickson (IQD) de plantas de Adenanthera pavonina em função da aplicação de diferentes doses de Azospoirillum brasilense em sementes.

\begin{tabular}{|c|c|c|c|c|}
\hline Doses de inoculante & MSPA (g) & $\operatorname{MSR}(g)$ & $\operatorname{MST}(\mathrm{g})$ & IQD \\
\hline $\mathrm{T}_{1}(0,0 \mathrm{~mL}) / 30 \mathrm{~g}$ de sementes & $1,37 \mathrm{a}$ & $1,22 \mathrm{ab}$ & $2,58 \mathrm{ab}$ & $0,50 \mathrm{a}$ \\
\hline $\mathrm{T}_{2}(0,3 \mathrm{~mL}) / 30 \mathrm{~g}$ de sementes & $1,45 \mathrm{a}$ & $1,04 \mathrm{~b}$ & $2,49 \mathrm{abc}$ & $0,45 \mathrm{ab}$ \\
\hline $\mathrm{T}_{3}(0,6 \mathrm{~mL}) / 30 \mathrm{~g}$ de sementes & $1,43 \mathrm{a}$ & $1,43 \mathrm{a}$ & $2,86 \mathrm{a}$ & $0,52 \mathrm{a}$ \\
\hline $\mathrm{T}_{4}(0,9 \mathrm{~mL}) / 30 \mathrm{~g}$ de sementes & $1,13 \mathrm{ab}$ & $0,87 \mathrm{~b}$ & $2,00 \mathrm{c}$ & $0,36 \mathrm{~b}$ \\
\hline $\mathrm{T}_{5}(1,2 \mathrm{~mL}) / 30 \mathrm{~g}$ de sementes & $0,96 \mathrm{~b}$ & $1,24 \mathrm{ab}$ & $2,20 \mathrm{bc}$ & $0,47 \mathrm{ab}$ \\
\hline $\mathrm{T}_{6}(1,5 \mathrm{~mL}) / 30 \mathrm{~g}$ de sementes & $1,41 \mathrm{a}$ & $0,94 \mathrm{~b}$ & $2,35 \mathrm{abc}$ & $0,43 \mathrm{ab}$ \\
\hline $\mathrm{CV}(\%)$ & 12,13 & 15,17 & 10,35 & 12,28 \\
\hline
\end{tabular}

Médias seguidas da mesma letra na coluna não diferem entre si pelo Tukey a 5\% de probabilidade. Fonte: Autores.

De acordo com Radwan et al. (2004), avaliando o efeito da aplicação de A. brasilense e Herbaspirillum em plântulas de trigo, constataram que ambos os gêneros de bactérias promoveram o acúmulo de massa seca da raiz e massa seca da parte aérea. Dartora et al. (2013) observaram efeito significativo para os parâmetros de massa seca da parte aérea e massa da raiz ao avaliar o efeito do uso de estirpes ABV5 e ABV6 de A. brasilense em diferentes híbridos de milho e trigo. Estudo realizado por Galeano et al. (2019) inoculando A. brasilense em sementes de milho, também permitiu verificar um aumento nos valores de massa seca da raiz de plântulas em relação ao tratamento sem inoculação.

Para o Índice de Qualidade de Dickson, as médias variaram entre 0,43 e 0,52 sendo que as melhores respostas foram obtidas no Tratamento T3 e na testemunha, porém, esses dois não diferiram dos tratamentos T2, T5 e T6 (Tabela 04). Autores relatam que o IQD é um parâmetro que indica a boa qualidade das mudas, visto que o seu cálculo considera a 
robustez e o equilíbrio da distribuição da biomassa. Entretanto, Gomes et al. (2002) afirmam que o IQD pode variar de acordo com a espécie, com manejo das mudas na casa de vegetação, do tipo e proporção do substrato, do tipo e volume do recipiente e, principalmente, conforme a idade em que a muda foi avaliada.

De acordo com alguns autores, solos considerados férteis podem afetar na expressão das bactérias presentes no solo e no inoculante, consequentemente, afetando nos efeitos positivos entre a interação de plantas e bactérias. Nesse sentido, observando à tabela 1 (material e métodos) as características físico-químicas do solo utilizadas para esse trabalho, são considerados ótimos para a produção de plantas devido aos bons teores de nutrientes e matéria orgânica presentes no substrato.

E de acordo com Araújo et al. (2016) a interação entre a planta, bactéria e ambiente pode ser afetado com o uso de solos férteis, autores citam que a boa disponibilidade de $\mathrm{N}$ nos solos pode inibir, mesmo que de forma indireta, a associação da planta com as bactérias diazotróficas, afetando na eficácia da fixação biológica de $\mathrm{N}$.

\section{Conclusão}

A aplicação de Azospirillum brasilense nas sementes de Tento Carolina (Adenanthera pavonina L.) não produziu maior crescimento das mudas em relação as que não receberam o tratamento.

Contudo, sugere-se para trabalhos futuros a alterações nas quantidades das doses de inoculação de Azospirillum brasilense podem ser mais eficazes no desenvolvimento de mudas de Tento Carolina (Adenanthera pavonina L.).

\section{Referências}

Aguiar, J. P. D. L. (2016). Inoculação de sementes com a estirpe 245 de Azospirillum: uma contribuição para o sistema de produção orgânico de mudas e flores de statice (Limonium sinuatom). Recuperado de: https://tede.ufrrj.br/jspui/bitstream/jspui/1478/2/2016\%20\%20Jo\%c3\%a3o\%20Paulo\%20de\%20Lima\%20Aguilar.pdf

Alves, M. M., Alves, E. U., Araújo, L. R. D., Araújo, P. C., \& Santos Neta, M. D. M. S. D. (2015). Crescimento inicial de plântulas de Adenanthera pavonina L. em função de diferentes substratos1. Revista Ciência Agronômica, 46(2), 352-357.

Cavallet, L. E., Pessoa, A. C. D. S., Helmich, J. J., Helmich, P. R., \& Ost, C. F. (2000). Produtividade do milho em resposta à aplicação de nitrogênio e inoculação das sementes com Azospirillum spp. Revista Brasileira de Engenharia Agrícola e Ambiental, 4(1), 129-132.

Dartora, J., Marini, D., Guimarães, V. F., Pauletti, D. R., \& Sander, G. (2013). Germinação de sementes e desenvolvimento inicial de plântulas de milho e trigo inoculadas com estirpes de Azospirillum brasilense e Herbaspirillum seropedicae. Global Science and Technology, 6(3).

Delarmina, W. M., Caldeira, M. V. W., Faria, J. C. T., Gonçalves, E. D. O., \& Rocha, R. L. F. (2014). Diferentes substratos para a produção de mudas de Sesbania virgata. Floresta e Ambiente, 21(2), 224-233.

Dickson, A., Leaf, A. L., \& Hosner, J. F. (1960). Quality appraisal of white spruce and white pine seedling stock in nurseries. The Forestry Chronicle, 36(1), $10-13$.

Domingues Neto, F. J., Yoshimi, F. K., Garcia, R. D., Miyamoto, Y. R., \& Domingues, M. C. S. (2013). Desenvolvimento e produtividade do milho verde safrinha em resposta à aplicação foliar com Azospirillum brasilense. Enciclopédia Biosfera, 9(17), 1030-1040.

Domingues Neto, F. J.; Yoshimi, F. K.; Garcia, R. D., \& Domingues, M. C. S. Influência de Azospirillum brasilense no desenvolvimento vegetativo, produção de forragem e acúmulo de massa seca da aveia preta (2014). Enciclopédia Biosfera, 10(18), 2013-2019.

Galeano, R. M. S., de Souza Campelo, A. P., Mackert, A., \& da Silva Brasil, M. (2019). Desenvolvimento inicial e quantificação de proteínas do milho após inoculação com novas estirpes de Azospirillum brasilense. Journal of neotropical agriculture, 6(2), 95-99.

Gomes, J. M., Couto, L., Leite, H. G., Xavier, A., \& Garcia, S. L. R. (2002). Parâmetros morfológicos na avaliação de qualidade de mudas de Eucalyptus grandis. Revista Árvore, 26(6), 655-664.

Gomes, J. M., Couto, L., Leite, H. G., Xavier, A., \& Garcia, S. L. R. (2003). Crescimento de mudas de Eucalyptus grandis em diferentes tamanhos de tubetes e fertilização NPK. Revista Árvore, 27(2), 113-127.

Gonçalves, R. H. (2019). Nitrogênio e fósforo no crescimento inicial de mudas de carolina (Adenanthera pavonina Linneaus). Recuperado de: http://www.repositoriodigital.ufrb.edu.br/bitstream/123456789/1587/1/TCC\%20Raissa\%20Corrigido.pdf

Gugé, L. M. A., Gugé, R. M. A., Coelho, B. S., Nascimento, F. M., \& de Castro Filho, M. N. (2019). Avaliação de técnicas de armazenamento de sementes de Tento Carolina (Adenathera pavonina L.) em função de diferentes tipos de embalagens e ambientes. Biodiversidade, 18(3), $126-135$. 
Research, Society and Development, v.10, n. 1, e4210111469, 2021

(CC BY 4.0) | ISSN 2525-3409 | DOI: http://dx.doi.org/10.33448/rsd-v10i1.11469

Hungria, M. (2011). Inoculação com Azospirillum brasilense: inovação em rendimento a baixo custo. Embrapa Soja-Documentos (INFOTECA-E). Recuperado de: http://www.infoteca.cnptia.embrapa.br/infoteca/handle/doc/879471

Maziero, C. L., Masiero, M. A., Leite, L. A. B., \& Klein, J. (2019). Desenvolvimento inicial de plântulas Anadenanthera macrocarpa (benth.) brenan) inoculadas com bactérias diazotróficas. Revista Científica Rural, 21(3), 104-117.

Monteiro, P., Winagraski, E., \& Auer, C. (2014). Importância do uso de rizobactérias na produção de mudas florestais. Embrapa Florestas-Comunicado Técnico (INFOTECA-E). Recuperado de: https://www.infoteca.cnptia.embrapa.br/infoteca/handle/doc/1010557

Oliveira Araújo, É., Vitorino, A. C. T., \& Mercante, F. M. (2016). Doses de nitrogênio e inoculação de Herbaspirillum seropedicae na cultura do milho em condições de solo fértil. Acta Agronómica, 65(1), 16-23.

Oliveira, C. D., Silva, B. M. D. S., Sader, R., \& Môro, F. V. (2012). Armazenamento de sementes de carolina em diferentes temperaturas e embalagens. Ciência Rural, 42(1), 68-74.

Pereira, P. C., Melo, B. D., Freitas, R. D., Tomaz, M. A., \& Freitas, C. D. J. (2010). Mudas de tamarindeiro produzidas em diferentes níveis de matéria orgânica adicionada ao substrato. Revista Verde, 5(3), 152-159.

Radwan, T. E. S. E. D., Mohamed, Z. K., \& Reis, V. M. (2004). Efeito da inoculação de Azospirillum e Herbaspirillum na produção de compostos indólicos em plântulas de milho e arroz. Pesquisa Agropecuária Brasileira, 39(10), 987-994.

Rampim, L., Klein, J., Tsutsumi, C. Y., Marchiotti, B. G., \& Guimarães, V. F. (2014). Desenvolvimento inicial de plântulas de Peltophorum dubium e Leucaena leucocephala inoculadas com bactérias diazotróficas. Revista Floresta, 44(4), 597-606.

Repke, R. A., Cruz, S. J. S., Silva, C. J. D., Figueiredo, P. G., \& Bicudo, S. J. (2013). Eficiência da Azospirillum brasilense combinada com doses de nitrogênio no desenvolvimento de plantas de milho. Revista Brasileira de Milho e Sorgo, 214-226.

Soares, P. G. (2007). Efeito da inoculação com rizóbio no estabelecimento, crescimento inicial e abundância natural de $15 \mathrm{~N}$ em leguminosas (Fabaceae) arbóreas nativas plantadas por semeadura direta (Tese de Doutorado, Universidade de São Paulo).

Veronezi, S. D. F., Ribeiro, L. M., \& Ceccon, G. (2018). Uso de Azospirillum brasilense em milho safrinha solteiro e consorciado com brachiaria ruziziensis. Revista Brasileira de Engenharia de Biossistemas, 12(4), 349-360. 